I Universidade de São Paulo (USP), Faculdade de Filosofia, Letras e Ciências

Humanas, São Paulo, SP, Brasil

gcohnog@gmail.com

https://orcid.org/oooo-oooI-590I-2506

Gabriel Cohn'

\title{
WEBER, ADORNO E O CURSO DO MUNDO
}

\section{DESTINO E PROMESSA}

Tais poderiam ser os termos para caracterizar dois modos de pensar radicalmente distintos, mas que se cruzam e se entrelaçam em diversos pontos e de diversos modos. Destino em Weber, promessa em Adorno. Tal é o tema mais fundo das presentes considerações, algo como um roteiro para trabalho de maior fôlego. E haja fôlego para o megaprojeto que nele se insinua: nada menos do que um exame em profundidade de duas grandes propostas de solução para os problemas das ciências sociais. Tais grandes propostas são aqui representadas pela ciência social analítica de índole compreensiva em Max Weber e pela sua contraparte dialética de índole crítica em Theodor W. Adorno. Trata-se de examinar esse confronto de posições, com o propósito bem definido de marcar precisamente isto: que se trata de duas configurações de pensamento em confronto e não de mero prolongamento de pontos centrais de uma em outra. Fundamental nesse esforço de interpretação é que ambas as posições são, cada qual a seu modo, tentativas de encontrar meios para fazer frente ao desafio mais amplo e mais fundo do conhecimento da sociedade. ${ }^{\mathrm{T}}$

São ambos pensadores indispensáveis, não é possível fazer justiça ao nosso tempo sem eles. São irmãos adversários, contudo. Na realidade, o simples confronto entre os dois não é suficiente, seria preciso introduzir no debate o terceiro termo. Pois é de triângulo que afinal se trata, com a majestosa figura de Marx ocupando o vértice superior. Não basta, pois, traçar uma linha entre 
dois pontos, é a complexa rede de forças entre os três que cumpriria desvendar, se firme fosse o ânimo e forte o braço. A ideia de fundo é clara. Não há como superar a radical incompatibilidade das formas de pensar representadas por Weber e Adorno. Salvo, é claro, o compromisso com a razão e com o conhecimento bem fundado a respeito do mundo, aqui e agora, e em seus desdobramentos.

\section{A ARTE DO EXAGERO}

Como colocar juntos dois pensadores tão díspares, habitantes do mesmo mundo e no entanto em perspectivas inteiramente diversas? O mesmo mundo, embora ainda nos prenúncios daquilo que poderia oferecer de pior no caso do severo Weber e já brutalmente escancarado para o hipersensível Adorno? A sólida fortaleza de um e o frágil caniço de outro? Um mundo que leva um deles a concentrar sua atenção no modo de condução da vida por agentes inteiriços e o outro a tentar decifrar a vida inapelavelmente frustrada? Um mundo com o mesmo fundamento histórico de índole capitalista, reconhecido por ambos embora os atingisse por ângulos inteiramente diferentes? Quando, diante de eventos adversos malgrado todos os esforços (no caso, a conduta do monarca prussiano na guerra de I9I4-I9I8), Weber proclama que "agora é destino, e com ele sabemos lidar", e Adorno dedica-se a deitar ao mar garrafas com mensagens para interlocutores em lugares distantes e tempos incertos? Quando Weber afirma que faz ciência para saber até onde pode suportar, e Adorno admite, sem ver razão para desculpas, que cada vez mais se dedica à arte?

Diante de tudo, não é de surpreender a atenção de ambos aos perigos dos limites e aos encantos da transgressão pelo exagero. Exagerar é minha profissão, diria Weber. Em Freud o que importa são os exageros, diria Adorno. Em áspera crítica a Adorno, Lukács criou a imagem do Grande Hotel Abismo, onde os praticantes da teoria crítica da sociedade se deliciam com as mais finas iguarias enquanto podem contemplar o vazio que se abre à sua frente. Atirou no que viu e acertou no que não viu. Abismo, sim. Esse é o ponto, não o conforto do grande hotel, aliás nem sempre disponível no exílio. Já nesse ponto revela-se que, apesar dos contrastes que veremos adiante, Adorno e Weber têm pontos importantes em comum. E um deles é o olhar ao mesmo tempo assustado e desassombrado para o abismo que, cada qual no seu modo, sabiam estar à frente, cientes de que ignorá-lo é, sim, cair nele. Encarar o severo semblante do dia, diria Weber. Não se conformar, diria Adorno. Como dar conta das armadilhas de uma razão que se projeta sobre tudo e se esquece de si própria, pergunta-se Adorno, em contraste com a visão weberiana do rígido habitáculo que ela tece com fios oferecidos por ações humanas. Obstáculos para ambos, com feições diferentes e modos diversos de enfrentar.

Como, enfim, se constrói um pensamento social teimosamente aderido ao limite do possível? É tarefa exaustiva e provavelmente com baixo proveito 
acompanhar passo a passo o desenrolar dessas duas formas de pensamento, atentas ambas às demandas e exigências do seu tempo e ao seu clima intelectual, em caminho que pode levar até a configuração psíquica dos autores, como já se tentou fazer em estudos biográficos. Não vamos aqui chegar a tanto. Nem por isso é preciso renunciar à historieta que ilustra um pouco a figura do jovem e altamente precoce Adorno. Intrigado com o interesse dele por Freud sem, no entanto, jamais ter procurado a psicanálise, membro do seu grupo de amigos recebeu a resposta, "mas como, você acha que ele iria se arriscar a perder sua neurose altamente produtiva"? Claro que esse prudente afastamento em relação à prática psicanalítica não impediu Adorno de se dedicar ao tema de múltiplas maneiras. Isso contrasta com a reserva de Weber na mesma matéria, explicitamente em nome de algo que jamais ocorreria a Adorno. A saber, a ideia de que enfrentar bravamente os "dilemas morais" que nos consomem sem recorrer a "alívios fáceis" é questão de honra. É tão difícil imaginar Adorno brandindo argumento tão aristocrático quanto vê-lo com cicatrizes de duelos estudantis no rosto (que, no caso de Weber, lhe custaram sonora bofetada materna, enquanto Adorno mal poderia conceber a ideia de a mãe sequer esboçar gesto de impaciência).

Diferenças, pois, mais do que semelhanças. Por caminhos cruzados, contudo. E suficientes para permitir a ideia de que nesses cruzamentos se encontraria muito daquilo que viria a marcar o pensamento social pelo século XX adentro, até nossos dias. Vamos, então, ao ponto. Embora haja semelhanças temáticas nas posições dos autores, os modos de pensar e as preocupações de fundo eram a tal ponto diferentes e mesmo opostos, que a afirmação de presença marcante de Weber na obra de Adorno dificilmente é sustentável. Para examinar isso, primeiro serão assinaladas algumas linhas de convergência, tomando-se como referência as ideias de Weber, para em seguida deslocar-se a ênfase sobre as divergências, em busca de um confronto abrangente das posições.

\section{CONSTRUÇÃO E COMPOSIÇÃo}

O próprio Adorno oferece aquilo que para ele parece ser o principal ponto de convergência com Weber, ao reservar espaço na sua Dialética negativa (nas páginas I42-I 44 da edição brasileira, publicada pela Zahar em 2009) para questão de método central para Weber, a da construção do tipo ideal. Seria mesmo improvável que Adorno deixasse de perceber aquele ponto, que afinal evoca procedimento central em sua formação e na sua prática nas diversas áreas a que se dedicou. Trata-se da ênfase de Weber, ao apresentar seu estudo sobre a ética protestante e o "espírito" (as aspas são dele) do capitalismo, no caráter gradativo, ao longo da pesquisa e da exposição, da emergência daquele principal recurso de método adotado por ele, o tipo ideal. Recurso, de resto, que exprime do modo mais cabal a presença, no cerne mesmo da sua pesquisa, da índole 
extremada de seu pensamento, numa espécie de exagero construtivo. A questão que despertou o interesse de Adorno consiste exatamente no procedimento construtivo de que Weber se vale e que, nos seus próprios termos, é o da composição. Isso significa que o tipo (do fiel calvinista ou do empresário capitalista, no caso) não se encontra pronto no início da pesquisa e só se apresenta em sua forma mais extrema, ideal, no seu término. Weber insiste em que mundo observado e conceito estão em planos diferentes e irredutíveis um ao outro. Entre eles medeia o motivo decisivo para a busca de conhecimento. Consiste ele no interesse que o cientista, como agente do conhecimento, dirige a tal ou qual traço distintivo nos processos efetivos. Claro que se poderia objetar que para Weber o papel de relevo no conhecimento social cabe à ideia de valor sustentada pelo agente, sem a qual não haveria como definir a área do real a ser pesquisada nem assegurar a relevância dos resultados. O valor, entretanto, não é intermediário de nada, é critério último de seleção e avaliação, no mais das vezes adotado de modo tácito. Está em outro nível em relação ao interesse, que aqui é invocado no mesmo plano que a ação, como orientação explícita que opera no seu interior. Em suma, e isso é fundamental, o interesse (na específica acepção em que é invocado neste ponto) compõe a vertente prática do valor, concerne à ação, e é isso que importa aqui.

Ao mesmo tempo, "traço distintivo" é expressão adequada, ao assinalar duas questões centrais. Em primeiro lugar, designa com precisão o caráter independente de tais traços e a isso acrescenta o essencial, a saber, que sua índole é diferencial, suscita distinções. Em segundo lugar, adverte para a importância do critério de seleção de tais traços; em suma, da orientação do interesse de quem seleciona, no caso o cientista. A resposta-padrão, a partir do próprio Weber, é que referências valorativas próprias ao agente do conhecimento o orientam na busca daquilo que importa, ou seja, é relevante (e não mero dado bruto) no interior de um universo empírico enumerável, embora finito, de opções possíveis. O fundamental é que em cada caso há uma relação de convergência, embora não de equivalência, entre a observação empírica, o objeto de análise e a orientação seletiva axiológica. No plano cognitivo e, intimamente associado a ele nesse processo, no plano valorativo, isso se resolve na formulação de problema relevante para a pesquisa. É nesses termos que na concepção weberiana de conhecimento científico ocupa posição central o problema e não a observação direta e análise de tais ou quais supostos dados empíricos imaculados. No plano da referência empírica dá-se que o problema proposto permite assinalar específicas linhas de ação, que envolvem agentes igualmente específicos. É na ação, ou seja, no complexo formado pelo encadeamento de atos intencionais unificados pelo sentido, que tudo se resolve, sempre lembrando que a ação propriamente dita não é intrinsecamente intencional. Importa se ela é ou não bem-sucedida; intencionais são os atos que a compõem. Nesse como em outros pontos Weber opera, embora nem sempre se modo explícito, 
com a concepção de um complexo de eventos significativos constitutivos de uma unidade. Isso se aplica à ação com a unidade de atos intencionais, assim como ao sentido como unidade de um complexo de referências significativas.

Desde seu âmago o pensamento de Weber se concentra na ação e não em valores ou coisas do gênero e ainda menos em algum objeto dado. O objeto do conhecimento deve revelar suas características ao olhar estritamente analítico do pesquisador, não como expressão de algo que o transcenda. Nada de "visão de essências", esbraveja ele já na abertura de seu livro sobre ética religiosa e capitalismo, de olho em seus contemporâneos encantados pela fenomenologia, "quem quer visões que vá ao cinema". É de características próprias ao mundo que se trata. Do ponto de vista do conhecimento é relevante a valoração, ou qualificação, na estrita medida em que exibe traço distintivo do objeto em questão. Com o que já neste passo se introduz o ubíquo recurso weberiano à comparação.

Em estreita correspondência a isso se encontra uma ideia que desempenha papel fundamental nesse modo de pensar. É a ideia de nitidez, sem a qual perdem arrimo as concepções weberianas de ação racional e de processo de racionalização. Isso é fundamental. Sem referências nítidas, livres de interferências geradoras de vagueza, não há como falar de ação social na sua expressão mais acabada. Não há como falar, enfim, de ação, sobretudo quando racional, isto é, com orientação inequívoca e despojada de quaisquer perturbações. Isso por mais que se admita, como Weber faz, que a ação efetiva de agentes empíricos no mais das vezes decorre contra pano de fundo confuso e obscuro. O recurso de método mais importante em Weber, o tipo ideal, é exemplo acabado disso, ao promover nos dados relevantes (isto é, já selecionados) precisamente o máximo de nitidez de seus elementos e das relações entre eles e assim abrir caminho para seu exame interno e sua comparação com outros complexos significativos, igualmente tomados como tipos. Orientação inequívoca. Tal termo é da maior importância no pensamento de Weber. Constitui o indispensável complemento para a ideia de nitidez, operando como sua vertente prática. A nitidez do objeto não se esgota em si mesma, e só exibe seu significado inteiro quando serve sem margem para dúvida na orientação da ação.

Bem diferente é o caminho de Adorno. Quando confrontados à ênfase weberiana na separação entre a ordem substantiva dos fenômenos e a ordem analítica de seu estudo e com a expressão disso na nitidez dos termos envolvidos, os procedimentos de Adorno têm algo de impuro. Falta-lhes a meticulosa ordem de cada coisa em seu lugar que marca o pensamento weberiano. Em Adorno o primeiro problema de método consiste precisamente em como alcançar rigor e validade na análise ao aceitar como intrínseca ao próprio processo de conhecimento a interferência da matéria examinada em suas condições de exame. E essa matéria é da ordem da experiência social. Nenhuma referência a uma razão pura, despojada de marcas da experiência, ainda quando limitada 
ou filtrada por referências valorativas, é aceitável para Adorno. A questão passa a ser, então, a de como estudar um objeto que insistentemente se intromete naquilo que está na própria base dos procedimentos cognitivos. Isso subverte a própria noção de objeto. Em vez de ser tratado como presença pura e dura, o primeiro passo consiste em contestar essa sua arrogância mediante a negação, ao se recusar a aceitar a condição de dado do objeto em sua compacta identidade e com isso expô-lo ao confronto com a alteridade e demonstrar que ela já está inscrita nele. A questão passa a ser a de como restituir a essa figura conceitual do objeto negado como tal a sua condição de origem, agora já inteligível, sem recair na sua concepção meramente afirmativa mediante procedimento que Adorno veria como "positivista". Isso de certo modo se aplicaria ao próprio Weber, quando ele segue no rumo oposto, ao atribuir ao pesquisador como sujeito do conhecimento o poder verdadeiramente senhorial de compor soberanamente seu objeto típico-ideal. (Sublinhem-se nisso dois termos decisivos no modo de pensar weberiano, senhorial e soberano).

Pode-se dizer que o objeto é construído tanto para Weber quanto para Adorno. Em acepções opostas, todavia. Se para Weber o sujeito-pesquisador constrói metodicamente o objeto sobre o qual incidirá a análise, em Adorno há construção (seria mais adequado dizer constituição) sim, mas prévia ao cuidado com o objeto que vai sendo constituído. Ele já aparece como produto, não do interesse cognitivo do pesquisador, mas das condições efetivas da sociedade em que se insere. Nesse sentido ele é plenamente objeto. Isso como resultado de condições igualmente objetivas, e o primeiro problema do pesquisador consiste em investigar o modo social como se dá essa sua constituição. É nesse passo que o objeto vê negada essa sua aparente condição de coisa dada e tem início a análise, precisamente pela reconstrução do modo como foi produzido ou, por outro ângulo, como foi composto. Não se trata, no caso, de análise de cunho genético em busca de origens ou trajetórias. Mais importa demonstrar como certos traços no objeto evocam traços da forma de sociedade em que ganhou sua figura própria - algo bem mais difícil do que reconstruir os passos de uma trajetória. Com certa liberdade de linguagem, trata-se de interrogar a memória no próprio objeto das condições de sua constituição.

Weber e Adorno, por maiores que sejam suas diferenças, ou precisamente por causa delas, preenchem com suas obras espaços contrapostos e de alta importância ambos. Weber representa em sua mais qualificada expressão o estilo robusto de quem quer enxergar as coisas de frente e desenhar, em todos os seus traços relevantes, um quadro fiel de aspectos do mundo diante dos quais é preciso tomar posição firme e sem ilusões. Se o mundo vai se tornando mais brutal, sua resposta é clara: é preciso tornar-se duro, numa espiral sem fim previsível.

A dureza de Weber com o mundo suscita resposta análoga no plano da concepção do objeto. O fulcro da análise é inequivocamente a ação, e essa, 
para alcançar índole social, ou seja, orientada para algo significativo, requer um específico agente. O problema que se põe é o da relação do agente com o sentido orientador da ação. E nisso, mais uma vez, Weber é duro. (Aqui, como em geral neste artigo, estamos diante de interpretação mais do que de reprodução daquilo que é explícito na obra). O sentido não é do agente, não encontra nele sua origem, e sim em seu entorno social. Não por acaso Weber estuda a ética protestante e o "espírito" do capitalismo e não o sujeito protestante e o sujeito capitalista. O agente converte-se assim em portador do sentido, mais do que seu "possuidor". É verdade que não há oposição entre ser "portador" e ser "possuidor". A questão se põe mais na distinção entre "posse" e "propriedade" ou "disposição sobre", sempre mantendo a terminologia weberiana. Ao agente não é dado acesso à propriedade do sentido, até porque isso lhe facultaria um nível de iniciativa própria incompatível com a arquitetura da relação entre sentido e agente. Pois então lhe seria facultada a busca daquilo que é central para Weber, o "monopólio", ou, por outro ângulo, a exclusividade da "disposição sobre" (o sentido, no caso). No cenário construído pela teoria desenha-se uma condição paradoxal, a saber, que o dominante é o sentido e não o agente.

Nessas circunstâncias o agente deixa de ser figura heroica para assumir a condição de subordinado. Por esse ângulo o agente weberiano guarda mais semelhança com o burocrata atento ao que convém aos mandantes do que com o intrépido desbravador de novos rumos. A referência aos mandantes tem destino certo. É que as figuras inseparáveis da escassez de recursos disponíveis e de sua apropriação diferencial estão presentes também no campo significativo. Pode parecer exacerbado falar nos agentes weberianos como meros portadores de sentido quando certos quadros institucionais se consolidam como dominantes. Sua conhecida observação segundo a qual os puritanos queriam ser homens de profissão e nós somos obrigados a sê-lo pode também ser lida em registro semelhante. Neste caso, enfatiza-se a outra observação de Weber no mesmo contexto, de que no capitalismo avançado a orientação da ação econômica dispensa a âncora religiosa do seu período heroico e impõe-se por si mesma. Isso pode ser visto à luz da ideia de que nesse quadro conceitual os sentidos para ações constituem recursos escassos como quaisquer outros e se convertem em objetos de apropriação diferenciada e, por conseguinte, de dominação. Isso numa situação paradoxal, pois dominante é o sentido e não o agente. Ou seja, em termos consentâneos àquela concepção weberiana, não se trata simplesmente da presença de orientações de ações afins entre si. É que uma específica consequência de sua conjugação significativa se torna dominante em seu contexto, abrindo com isso o caminho para a conversão de condutas estritamente individuais em "fenômeno de massa", para usar expressão não alheia a Weber. A ideia, no caso, é que a posse de determinado sentido é compartilhada de modo regrado por numerosos agentes, sob o influxo do sen- 
tido dominante. Nesses termos, vai prevalecendo a lógica da articulação significativa, mais do que quaisquer atos intencionais de agentes, que passam de originários a portadores de sentidos. No mesmo passo estes de certo modo se rotinizam, tal como ocorre com a dominação carismática estudada por Weber. Naquela, tal rotinização, tal absorção no cotidiano permite superar a crise da transmissão do comando e abrir caminho para lideranças não ungidas pela graça carismática. No caso que aqui importa, aquele processo, sob a forma da institucionalização, vai se generalizando em ambiente marcado pela ação racional.

\section{O LEMA FUNDAMENTAL}

A posição de Adorno está em outro quadrante. Além do cuidado com aproximação por vias indiretas do objeto e da exigência da análise imanente, Adorno pode ser visto como o patrono máximo, sem ser o autor (em árdua disputa com Simmel), daquilo que me parece ser o lema fundamental para a pesquisa social nas condições contemporâneas. Quanto mais bruto o mundo, mais fina deve ser sua análise, esse é o lema. Não se trata de imperativo vazio, nem de desqualificação da pesquisa estilo hard com todos os meios de coleta e tratamento de dados a que tem direito, sendo, como é, passo indispensável na produção de conhecimento social. A ideia é que, nas condições presentes e presumivelmente em futuro próximo, com as múltiplas formas que vai assumindo o capitalismo como centro nervoso da sociedade global e a resultante complexidade crescente dos processos e relações, gera-se um efeito específico. É que seu entendimento exige um alto nível de finura e mobilidade na formulação do problema e na condução da pesquisa. Isso é necessário para impedir que a imaginação sociológica fique tolhida pela brutal evidência de problemas visíveis a olho nu por todos os lados. A "vontade de mudança" reclamada por Adorno num momento de feliz exaltação (em artigo sobre "o conflito social hoje") nunca esteve tão ligada à atenção ao mínimo, ao insignificante, ao efêmero, sem o que o conhecimento positivo e a crítica ficariam inermes diante de sua absorção na reprodução do estado de coisas vigente.

Para Adorno é no mais recôndito, no elo mais frágil apesar de sua aparente firmeza, que se pode, no momento mais insuspeitado (o Messias só vem quando não é esperado, diria Kafka), chegar a fazer aquilo que ele em certo momento assinalou como "erguer a pedra sob a qual viceja o monstro". É verdade que para desenvolver melhor isso seria preciso examinar a fundo a face contemporânea do monstro, naquilo que a tradição marxista chamaria de contradições do capitalismo na sua forma social, de conflito de classes. No modo de pensar de Adorno, com sua inspiração marxista pouco ortodoxa, encontra-se nisso a convivência simultaneamente firme e vulnerável de traços básicos de um complexo histórico (ou seja, social, político, econômico, cultural, espacial e tudo o mais) marcado pela solidez de sua parte material de um lado e pela 
fragilidade dos construtos imateriais (gadgets financeiros de toda sorte, por exemplo, sem falar dos processos ideológicos) que sustentam o funcionamento do conjunto. Em quem confiar mais: no duro e inflexível Weber ou no ultrassensível Adorno?

\section{O QUE DIZ A PESQUISA}

Nesta altura talvez sejam úteis referências obtidas na pesquisa efetiva. Tomemos inicialmente construtos weberianos de figuras como a do tipo de ação religiosa calvinista e do tipo de ação econômica capitalista moderna. Interessam, nesse caso, as relações entre aqueles tipos de ação. Mas tipos não se relacionam sem mais, valem cada qual por si. Para estabelecer conexões significativas entre eles é necessário um agente em que aquelas modalidades de ação possam estar presentes simultaneamente (por vias próprias, contudo) como portador dos respectivos significados. Em suma, importa localizar um agente social que é (ou seja, que age como) ao mesmo tempo calvinista e capitalista. Isso para chegar ao que importa, que é saber se tais modalidades de ação convivem ou brigam entre si (no mínimo, se há ou não entre elas algo daquilo que mais tarde o psicólogo social Leon Festinger denominaria dissonância cognitiva) ao imprimir seu timbre na condução da vida (de novo trazendo termo do repertório weberiano e ausente no de Adorno, para quem a ideia de que alguém conduza sem mais sua vida só caberia mesmo numa concepção senhorial do mundo). Temos, então, traços independentes que se compõem no tipo e, em segui$\mathrm{da}$, tipos igualmente independentes cujas conexões a pesquisa busca descobrir.

Tudo isso convida a trazer Adorno para confronto. Interessa aqui o momento em que ele exerceu papel de relevo no desenho e na condução da grande pesquisa realizada nos Estados Unidos na década de I940, sobre a personalidade autoritária. Trata-se efetivamente de trabalho de equipe de cunho interdisciplinar. O objetivo da pesquisa era importante e oportuno, e também bastante heterodoxo nas ciências sociais norte-americanas. Tratava-se de interrogar-se sobre a presença de traços autoritários propícios à aceitação de posições fascistas naquele ambiente supostamente avesso a tanto. Ao fazê-lo, contribuiu na construção e aplicação de instrumento de análise que ainda hoje, talvez mais do que nunca, merece atenção. Trata-se da Escala F (F de fascista), a parte da pesquisa em que a colaboração de Adorno foi mais direta, desenhada para detectar traços de percepção do mundo e de conduta de pessoas que obtenham alta pontuação ao responder às questões que a compõem e com isso revelem indícios daquela síndrome que a equipe denominou personalidade autoritária. Tomadas isoladamente, as questões correspondentes a itens da escala não parecem especialmente significativas. Tomadas no seu conjunto e com atenção para significados subjacentes aos expressos, todavia, revelam alta capacidade de prever determinado tipo de personalidade, de índole autoritária. Convém lembrar, contra frequentes equívocos, que a pesquisa não tinha 
por alvo direto o fascismo ou os fascistas. Seu cerne é a propensão à conduta autoritária e, por extensão, a vulnerabilidade a posições fascistas. Procura-se detectar atitudes (ou seja, disposições para agir) antes de linhas de ação efetiva. A primeira coisa a ressaltar é que as questões envolvidas não são diretamente referidas àquilo que importa detectar e suas respostas operam mais como indícios de algo do que como sua identificação. Esse modo indireto de conduzir a pesquisa, sempre de olho naquilo que não se encontra presente sem mais e só aos poucos emerge do conjunto de olhares, é importante legado metodológico que seguramente deve muito a Adorno. Weber mal esconderia sua impaciência diante desse modo sinuoso de chegar ao ponto.

A escala F não é aplicada isoladamente, só ganha sentido quando examinada junto com os resultados de entrevistas individuais em profundidade, no caso sob a orientação da psicanalista integrada na equipe da pesquisa (pesquisadores excelentes, que despertaram o respeito de Adorno apesar de meros "positivistas"). O essencial, contudo, é que nenhum item da escala faz sentido fora de sua relação com todos os demais, e o resultado de sua aplicação só ganha pleno sentido em sua relação com outros instrumentos, como a história de vida explorada nas entrevistas e os testes psicológicos projetivos, como o TAT. Seria possível, entretanto, assinalar que certas pontuações frequentes na aplicação da escala, em especial quando relacionadas àqueles outros enfoques na pesquisa, são designadas na exposição dos resultados em termos como "tipo de personalidade manipuladora" ou "rebelde". Entretanto, tais designações não desempenham papel de tipo ideal, restringem-se à condição de nomes, de identificadores nominais. Sobretudo, não foram construídos para tanto. Tratase, mais propriamente, de aplicação de análise sociopsicológica para captar configurações de personalidade. Configurações é termo adequado, porque a atenção está mais voltada para a associação de traços do que para seu isolamento. Não se trata de exacerbar traços com viés comparativo como se faria com o tipo ideal, e sim de chegar ao significado de específicas combinações deles. É de suspeitar que Adorno, que participou diretamente na redação final dessa parte da pesquisa, tenha tido seu papel na atenção às associações organizadas de traços mais do que desses tomados em si mesmos. Convém ainda lembrar que a ênfase na análise de cunho psicológico centrado na personalidade não significa, como Adorno se esforça por salientar, que se estivesse procurando explicação psicológica para o autoritarismo e, no limite, para o fascismo. A questão consistia em buscar o entendimento da aceitação e propagação de percepções, de modos de pensar e de ações autoritárias pelas numerosas pessoas que poderiam constituir a base social para regimes dessa índole.

\section{DISTANCIAMENTO E APROXIMAÇÃO}

Na construção do tipo ideal sobressai o estilo de Weber: nitidez, coerência, univocidade, marcas de um pensamento linear e vetorial que se mantém à 
distância de seu objeto. Sem por isso ser pobre, contudo. Igualmente importam nele as afinidades, as ressonâncias entre as linhas vetoriais em seus trajetos diferenciados, naquilo que à primeira vista seria o mais forte ponto de encontro com Adorno. Mas não é bem assim, pois os autores trabalham em registros diferentes. Em primeiro lugar, o pensamento de Weber é causal de ponta a ponta. Expressões como "afinidades eletivas", já altamente expressivas por si mesmas, servem mais para sugerir possíveis relações causais, ao passo que Adorno está voltado para a decifração de complexos particulares de relações para neles detectar o modo de presença do entorno social mais amplo. A ques tão não é tanto a de Weber, de identificar como causa o tipo de ação responsável (termo central nele) pela presença de tais ou quais traços em outros. Tratase mais de detectar o modo como o fenômeno social em questão ganha suas qualidades específicas em suas relações com o entorno social mais amplo e destarte se torna determinado.

No pensamento adorniano ganham relevo os atos de aproximação e envolvimento do objeto, de acercar-se dele (a aproximação, o achegar-se é central em Adorno). É uma forma de conduta para a qual não é abusivo o termo mimética, desde que ele seja liberado de qualquer referência à imitação e trazido para nossa área de interesse. Nela, traduz um empenho de índole simpática (Adorno odiaria este termo, que lembra autor que não apreciava, Max Scheler), não mera identificação, antes um impulso para aproximação marcada pela plasticidade e pelo caráter ativo, que elimina a mera repetição do objeto e de algum modo o transfigura não como espectro e sim com seus traços mais fundos à mostra. É nesse sentido que faz sentido o ato de imergi-lo numa configuração conceitual até ele se revelar "com suas fendas e fissuras à mostra", para usar expressão pungente na conclusão de Minima moralia. Trata-se de um modo de aproximar-se do objeto ao negá-lo como mero objeto, ao vê-lo como forma específica de determinada matéria, que é visceralmente social.

Aqui, uma rápida digressão. Não deixa de ser fascinante, por aquilo que sugere de afinidades entre campos muito diferentes do conhecimento, ser informado de que o matemático Alexander Grothendiek (apátrida, anarquista, herege até o último fio de cabelo, duríssimo em suas exigências éticas) considerado um dos muito grandes do século XX, recomendava como modo de enfrentar um problema duro cercá-lo por todos os lados, como que o mergulhando na água até fazê-lo amolecer e revelar seu segredo. Aqui, como em tantos outros casos, pensadores que enfrentam de modos inteiramente diversos aspectos do mesmo mundo encontram soluções semelhantes para problemas muito distantes entre si. Nesse caso específico, em que se trata de incluir o objeto em algo envolvente como um ambiente, encontramos um modo de seu tratamento que pode ser chamado de impregnação, o exato oposto do ato de mantê-lo distante e livre de interferências. Por outro lado, não seria recomendável colocar Weber e Grothendiek à mesma mesa. Por mil razões, menos uma. 
Não que Weber fosse indiferente à matemática. Pelo contrário, como revela observação casual em sua fala sobre ciência como profissão (mais do que como vocação) a respeito de Weierstrass, o mestre e apreciador de Husserl como matemático, para invocá-lo como paradigma de imaginação científica.

Em Weber, pois, trata-se de distinguir o objeto mediante caracterização adequada. Já em Adorno, de abri-lo ao conhecimento mediante suas relações com outros. A análise weberiana opera por distanciamentos metódicos e bem controlados do objeto, estribados no imperativo da isenção valorativa (ou neutralidade, para usar o termo corrente, pouco preciso). Por isso mesmo o recurso de método mal denominado "compreensão" nada tem a ver com empatia, e tudo com o entendimento de sequências de atos intencionais que se condensam em sentido e por essa via em ação. E o exercício da ação nada tem a ver com móveis psicológicos no agente, deve-se à orientação (termo fundamental em Weber) para certa meta. Nesse sentido, a compreensão significativa assume mais propriamente o caráter de entendimento da orientação da ação do que de imersão empática. No mesmo passo elucida-se também a questão do significado de sentido. Para além de ser a meta da compreensão, a operação do sentido permite escapar da pura referência a entes e processos, que por si próprios se estenderiam num encadeamento infinito de eventos. Isso é feito exatamente ao se atribuir sentido a uma específica parcela deles. Ou seja, o sentido não é algo que preexista à ação, senão somente se faz valer quando é objeto de atribuição - e com êxito, o que representa parcela fundamental do problema. Pois, afinal, se o sentido não é ente rombudo que se impõe à conduta da ação, tampouco é coisa etérea, que pode ser invocada sem mais em qualquer circunstância. A emergência do sentido é condicionada por um conjunto de restrições impostas em cada caso pela situação. Constitui, assim, expressão paradigmática daquele problema com que se depara o cientista na composição de seu objeto, ao estabelecer por sua conta um limite no interior do inumerável campo dos fenômenos. Nessa perspectiva, o sentido atua em duas frentes. Por um lado, permite fazer um específico corte naquele encadeamento potencialmente infindável de fenômenos sociais e, por outro, confere unidade ao conjunto, obtido mediante uma decisiva seleção. Isso tudo se dá contra o pano de fundo da afinidade do tema do sentido com o de orientação, que se traduz no caráter vetorial e não apenas linear daquilo que venho denominando linhas de ação.

Essencial nisso tudo, todavia, é o caráter da referência a um sentido que, na concepção corrente, se atribui ao agente social na efetivação da ação. Como caracterizar tal referência, qual é afinal a relação que nisso se estabelece entre sentido e agente? Numa específica perspectiva pode-se conceber, como Max Weber faz, o agente como portador de sentido, desde que este, num cenário altamente racionalizado, tenha alcançado elevado nível de autonomia. Em geral, entretanto, não é isso que ocorre. O agente não se apresenta unicamente 
como portador de sentido, tem papel ativo a desempenhar. Em termos amplos pode-se sustentar desde logo que o agente não se reduz, salvo em situaçõeslimite, a sustentáculo do sentido, nem a fonte do qual este emana, nem tampouco ao resultado da operação de sentido (uma concepção que nos aproximaria de Adorno). Falar em operação de sentido nos remete ao ponto que importa. O agente social é, mais propriamente, operador de sentido, o que significa que a relação do agente com o sentido não é de controle e ainda menos de propriedade, e sim de capacidade de agenciar relações significativas (ou seja, dotadas de sentido), de modo que se converta em ação efetiva o encadeamento puramente lógico de termos de um processo. Sem ele a névoa significativa que envolve cada ação resultaria em indefinição, para ficar com termo que Weber aceitaria. Dizer que o agente é "mais propriamente" um operador remete ao ângulo original de nossa questão. Qual é, afinal, a relação entre agente e sentido no curso da ação? Aqui volta a nos atormentar a questão das nuanças de certos termos alemães, que os tornam de tradução tão dificultosa e tão sujeita à imprecisão. No caso está em jogo a expressão gemeinter Sinn, na qual o primeiro termo, a fonte de nossas preocupações, modifica o segundo, que significa "sentido". A solução mais encontradiça em português (e em francês, de onde proveio) é que há um sentido "visado" pelo agente ao realizar a ação. Em variantes da língua espanhola se diria "mentado", aproximando-se da posição sustentada aqui. Já no primeiro passo a dificuldade consiste em que na ação o agente não tem por objeto de atenção algum sentido. Não se visa ao sentido, este é o ponto. Visa-se a uma meta, e o sentido oferece a orientação para chegar a ela. Sem dúvida, a meta é significativa para o agente, como condição de sequer haver ação. Mas, sentido e meta não se confundem. E é exatamente isso que ocorre quando se fala em sentido "visado". Para fazer frente a essa dificuldade convém ir à sua origem. Também aqui o caminho consiste em examinar a expressão alemã usada por Weber, que é "gemeinter" Sinn e na qual primeiro termo é derivado do verbo meinen. Em primeira aproximação ou no dicionário meinen significa achar, considerar, julgar. Significa, em suma, assumir posição própria diante de algo, o que já é da maior importância em nossa argumentação. Além disso, e de modo um tanto temerário mas não abusivo, outro aspecto no mínimo sugestivo consiste na possibilidade (por analogia e não por rigoroso estudo etimológico) de nisso encontrar uma raiz do termo, que seria mein, ou seja, meu. Haveria, assim, incorporada no termo usado por Weber a ideia de posse. Essa dimensão fundamental do conceito weberiano, que suscita a ideia de que o agente "se apossa" do sentido, fica perdida nas traduções habituais. Ela é mais forte do que aquilo que termos como "visado" ou mesmo "pretendido" exprimem. O que está em jogo, em termos mais exigentes, é algo como ter em mente, com ênfase no "ter", em apropriar-se. O agente não é passivo, ou não seria agente; mas também não é poderoso. Sua capacidade de apropriar-se do sentido é uma orientação da ação e não um ato autônomo. 
Para Adorno, todavia, é essencial a capacidade, também metódica, de captar intimamente, a partir de dentro, o modo como o objeto se organiza e opera por seus próprios meios. Trata-se, no sentido mais preciso do termo, de análise imanente ao objeto. Pouca valia tem a caracterização externa do objeto de pesquisa, muito menos perder-se nele. Importa penetrar sua casca, acompanhar de perto sua pulsação interna, para retornar (é aí que está o segredo, e é por isso que cabe falar da pesquisa social como experiência) em condições de entender suas relações com outros e, sobretudo, o modo como incorpora em sua forma o entorno social mais amplo.

A referência à lógica (não no estrito sentido técnico) toca em questões centrais em nossa área de interesse. Se nos ativermos ao termo estaremos mais no terreno de Weber, onde ele encontra condições especialmente favoráveis de emprego. Isso se dá pela afinidade que guarda com as ideias de nitidez, coerência e univocidade, tão caras a ele. Nessa perspectiva restrita, lógica pode ser entendida como uma propriedade de processos significativos, sempre que eles exibam um encadeamento internamente coerente de elementos. Essa acepção estreita é suficiente para nos conduzir ao cerne do confronto entre os dois modos de pensar a ciência social que nos ocupa. Consiste ele nas concepções defendidas por um e outro naquilo que concerne à racionalidade da ação e das relações sociais e, por outro lado, ao processo secular de expansão do âmbito racional nos diversos campos da ação social e das instituições, a racionalização.

Cabe aqui um desvio na ordem de argumentos que vêm sendo propostos. A questão da racionalidade e da racionalização mereceria análise comparativa mais detida naquilo que concerne ao confronto entre as concepções de Weber e de Adorno. Até porque Adorno é explícito, em pelos menos uma de suas raras referências a Weber, quanto à importância da análise weberiana do papel da racionalização dos meios e da linguagem musical ao estudar as características da música historicamente desenvolvida na Europa ocidental. Sobre isso, entretanto, vou me abster, até porque há excelente fonte entre nós. Refiro-me à apresentação e às notas que Leopoldo Waizbort juntou à sua tradução, de I 995 na Edusp, do texto weberiano Os fundamentos racionais e sociológicos da música.

A concepção weberiana de racionalidade (no sentido de padrão de orientação de ações e não como qualidade abstrata) envolve a síntese dos três atributos já mencionados, a coerência, a nitidez e a univocidade. Isso tem por consequência o deslocamento, embora não a rejeição, da relação habitualmente invocada para identificar a racionalidade, que é aquela entre os fins almejados e os meios mobilizados para os atingir, concentrando-se a posição racional na escolha mais eficiente dos meios. É que, na perspectiva aqui adotada, a racionalidade vai mais fundo. É precisamente ela que permite discernir meios e fins, em distinção fundamental que a ela se deve. Ocupa posição fundante e não de mero instrumento. É mediante essa distinção que se abre caminho para o agenciamento mais eficaz, logo mais racional nessa perspectiva, dos recursos pertinen- 
tes. Em Weber o processo consiste em um encadeamento de ações no tempo, ordenado e com orientação discernível (sem teleologia, contudo, a meta perseguida na ação é inteligível sem deixar de ser contingente). Em Adorno, por sua vez, não encontramos processos lineares e retilíneos, eles carregam consigo toda sorte de perturbações. Nele o processo não é visto como sequência de itens independentes, mas, em linguagem ainda enigmática, como o modo de movimento do objeto, como relações se entrelaçando dinamicamente.

\section{LÓGICA E LEGALIDADE}

Até aqui estamos mais no universo weberiano do que no adorniano. Um passo a mais, todavia, nos leva a terreno bem mais escarpado, em que as aproximações e distanciamentos entre ambos se tornam mais fortes e mais intrincadas. Comecemos novamente com Weber. No centro mesmo de seu esquema analítico encontra-se ideia especialmente engenhosa, sem a qual sua armação conceitual não teria como se sustentar. Trata-se da ideia da "legalidade própria" (o outro lado da "lógica própria) a cada linha de ação, entendida como encadeamento de atos significativos. Isso significa que ao se desenrolar cada linha de ação segue por sua própria via, que não se confunde com nenhuma outra. Para usar imagem de Weber em outro contexto, cada uma segue de modo autônomo seus trilhos específicos. Para a mente "ferroviária" de Weber, afeita a vias e direções bem definidas, é de imaginar seu fascínio pela fundamental questão de método que então ser apresenta. Como estabelecer relações entre entes que não dependem de quaisquer outros para seguir seu caminho? Como sabemos, é pelo lado das afinidades ou rejeições de significados em linhas diversas, mas não indiferentes entre si (este é o ponto) que a coisa se resolve. Não é na concepção do tipo ideal, que ele nem mesmo atribuía a si, nem no foco na ação social, nem no cuidado com a dimensão significativa da ação que se encontrará Weber em sua potência máxima. É na ideia da autonomia das linhas de ação. O que está em jogo não é o aspecto formal de tal autonomia, e sim o modo como incide na capacidade de orientar ações. Ou seja, a atenção se concentra nas consequências da ordenação interna, pois ela de nada vale se não servir para suscitar ações de determinado tipo. O essencial é que essa lógica ou legalidade intrínseca oferece caminho bem definido em cada caso para as ações, sempre se considerando que a concepção weberiana tem duas faces, a da consistência interna da "lógica" e a do caráter imperativo da "legalidade".

Para o olhar de Weber tal lógica exibe inquietantes sinais de estreitamento no mundo que o cerca. Com uma agravante. É que no mundo moderno um processo decisivo imprime sua marca em todo o resto. Refiro-me à tendência à racionalização de todas as linhas de ação. Vale dizer, é a expansão cada vez mais inexorável do padrão de nitidez inequívoca e unívoca que vimos acima, que ao avançar leva consigo, como exigência interna, aquela diferenciação 
de linhas de ação significativa de que falamos. A ideia é que, posto que as ações obedecem às exigências da conduta racional nos termos de suas legalidades próprias, duas consequências importantes se apresentam. Primeiro, elas vão se tornando cada vez mais diferenciadas, cada qual com sua orientação específica. Segundo, junto a isso elas vão se tornando mais rígidas e estereotipadas (o termo é dele), com crescente intolerância à variação de sentido. O ganho de eficiência propiciado pela capacidade de cálculo acaba sendo compensado pelo caráter previsível e insípido do mundo assim criado. É um mundo que reserva posição de crescente relevo para a organização e a atividade daquilo que Weber denomina quadro administrativo, essa agência de gestão eficiente que vai se tornando indispensável em todos os quadrantes. Não se trata de burocratização em sentido literal; o mundo não se converte em mero acúmulo de aparatos burocráticos, mas estes vão marcando presença em todas as áreas, em nome da racionalidade e consequente eficiência da gestão de recursos inapelavelmente escassos (esta última formulação é fundamental).

Àquela proliferação de aparatos burocráticos pontuais responde a concepção adorniana da "sociedade administrada", muito próxima àquilo que outros denominariam "sociedade de controle". Nesse caso a ênfase recai na estreita combinação entre os dois termos, sociedade e administração, que se reforçam mutuamente. Motivo de alarme para Adorno é o modo como essa conjugação suscita a ameaça máxima, aquela da constituição da sociedade como totalidade com um centro aglutinador. Aqui não é a orientação dominante da ação que importa, mas a prevalência de um todo constituído em sistema com ordenação estrita, que atropela quaisquer instâncias parciais e converte os indivíduos em peças subordinadas suas. Neste ponto transparece uma vez mais a distância que separa a atenção de Weber no agente individual como unidade última da ação e neste sentido não problemático, e a concepção crítica de Adorno, quando vê a individualidade como aquilo que há de mais problemático no modo de organização contemporâneo da sociedade sob o império do capital.

A questão básica para Weber consiste no aspecto inexorável daquele processo de racionalização uma vez posto em movimento. Cabe aqui lembrar um desdobramento de grande importância, a saber, que a ação racionalmente orientada não substitui as outras. Ela as subordina a si, torna-se dominante de modo cada vez mais inabalável (como a orientação racional faz com a mágicaencantada).

\section{RAZÃO E RACIONALIZAÇÃO}

A razão é totalitária, afirmam Horkheimer e Adorno ao discutir a "dialética do esclarecimento", naquele que talvez seja o ponto em que mais se aproximam as concepções weberianas e as da Teoria Crítica. Weber não usaria aquele termo não só porque não estava disponível no vocabulário de sua época (ele só passou 
a ser usado, em registro positivo, no fascismo italiano) como também porque sua atenção ansiosa concentrava-se mais em seu caráter internamente inexorável do que naquele da expansão externa. É nessa dimensão interna do mundo racionalizado que cada passo demanda um e um único passo seguinte, sem haver como escapar dessa via - salvo por mudança completa das regras do jogo, mediante a criação de novos fundamentos últimos da conduta, de novas orientações valorativas enfim. É difícil considerar a mescla de resignação e de postura escatológica na posição de Weber diante do enrijecimento do mundo racionalizado sem lembrar a frase desalentada de Martin Heidegger algumas décadas e duas catastróficas guerras depois, "só um deus poderá nos salvar".

Fale-se o que se quiser do pessimismo de Adorno, sua visão de uma redenção difícil e nem por isso impossível era inteiramente secular, inteiramente infensa a voos proféticos. Não cheguemos, contudo, a ver tais voos na igualmente secular visada weberiana, ainda quando essencialmente diversa daquela de Adorno. O principal traço dessa diferença consiste na índole de suas conclusões de análises, repletas ambas de história presente. Em Weber seus maiores comentários sobre as consequências daquela grande tendência em termos históricos assumem um pungente tom prospectivo ("um gélido inverno nos espera"), de quem está às voltas com o grande tema do destino. Já em Adorno o olhar também se dirige para a frente, para um porvir indefinido, mas por ângulo inteiramente diverso, compatível no fundo a uma bem fundada confrontação ao impossível. Num momento de entusiasmo, talvez (até porque escrevia o já mencionado artigo sobre "conflito social hoje", e isso junto com uma estudante, o que para ele não era de somenos), ele encontra como fundamento daquela posição a vontade de mudar. Nele o tema fundante é o da promessa. E esta, vista pelo ângulo adotado aqui, envolve o compromisso com a persistência de atos de vontade de mudar, por ínfimos que sejam, nunca se sabe. Cabe lembrar, neste ponto, que a ideia de promessa não se confunde com a de esperança. Esta é basicamente uma atitude passiva e pouco afeita ao ato efetivo. Já a ideia de promessa, em especial no modo como aqui se sugere que podemos ler Adorno, é performativa, envolve compromisso com a ação, sem, no entanto, oferecer segurança de êxito. Encontra-se nisso desconcertante ponto de convergência entre ele e o politólogo polonês Adam Przeworski, que propôs o lema "ama a insegurança e serás um democrata". Pode-se dizer que há algo de resignado no destino weberiano e algo de subversivo na promessa adorniana, por mais pessimistas que ambos sejam com relação ao mundo e seu futuro caso suas tendências não viessem a se modificar radicalmente.

A divergência entre Weber e Adorno nessa área vai fundo. Para Adorno a imagem da via inescapável era o que havia de pior. Semelhante nisso a Weber, ele levava muito a sério a restrição da latitude de opções e o gradativo enrijecimento dos significados que as orientam. Todavia, não se trata para ele de processo que se desenrola por efeito de uma dinâmica própria, marcada pelo 
predomínio inapelável da orientação racional da ação. Como sempre, nele cabe ver o processo como produto, o que significa não se deter nele senão decifrar as condições que o suscitam. No caso, é o modo de organização do capitalismo como processo histórico multidimensional que oferece tais condições e impõe seus resultados, como diretrizes e não como coisa feita. É para ele, então, que cabe dirigir como meta final o esforço de conhecimento. Também nesse ponto se manifesta o lema fundamental do empreendimento adorniano: onde todos os demais encontram a pedra dura, cabe seguir pensando, levar adiante o questionamento, recusar a mera positividade. Não há via única, assim como não há pensamento único. O acanhamento do léxico significativo e, em consequência, da margem de opções é possível e realmente ocorre, dadas as tendências da sociedade. Mas, em princípio, é igualmente possível sua expansão, por baldado que pareça o esforço para tanto em dado momento.

$\mathrm{Na}$ realidade, é de considerar que permanecer contido nas estreitas margens da única via acessível não se resumia em nenhum dos dois mestres a algo como um símile espacial para a coerção. Isso por mais que para Weber tal estreitamento fosse inexorável na sua lógica interna, entendida como diminuição da latitude de significados na ação (uma forma possível de ver o chamado desencantamento). Para ele o problema da via racionalizada que desemboca no destino envolve estreitamento, em sentido muito específico. É que ele não implica mero constrangimento externo, como à primeira vista é sugerido pela célebre imagem do "férreo habitáculo" (ou prisão, gaiola, revestimento, crosta e por aí afora) em que penetramos impelidos pelo processo de racionalização. O que mais de perto o preocupa é a redução significativa, o empobrecimento do campo de ações disponíveis (ou seja, dotadas de eficácia). Em suma, o estreitamento do destino. Por essa perspectiva, é expressão daquilo que poderíamos chamar de paradoxo da racionalidade na teoria da ação weberiana. Pois, à medida que a orientação estritamente racional da ação avança, dá-se a passagem do campo aberto da ação, que ocorre no interior de situações contingentes envolvendo agentes, para a ordenação objetiva do sistema. Weber não é somente testemunha do apogeu da organização da ação social em torno de agentes individuais em situações dotadas de significado. Ele anuncia, com rigorosa e dolorosa convicção imposta pelos fatos, o encerramento desse período histórico e a emergência de seu destino.

Para Adorno, por seu turno, o que desponta à frente, em futuro indefinido, não é o encerramento do destino, mas um processo bifronte. Por um lado, a continuidade da tendência (pois é sempre de tendência que se trata) para a explícita constituição da sociedade na forma de uma totalidade centrada na reprodução do capital. É essa tendência que ele incansavelmente vai encontrar sob mil formas no modo como a sociedade vai se apresentando em todas as suas manifestações, até naquilo que tem de mais recôndito. Pois é aí que o caráter do conjunto melhor se exprime, na presença ou, como possibilidade 
remota porém real, na ausência dos traços que sinalizam seu predomínio. São os indícios da supremacia do todo, do geral sobre o particular, que Adorno persegue e repudia implacavelmente. Isso lhe angariou a imagem de empedernido pessimista, quando não derrotista. Entretanto, se é de um processo que se trata, seu integral fechamento não está assegurado, é um ponto de fuga, não se reduz àquilo que se apresenta em cada momento. Isso significa, desde logo, que a negação que inerva (o termo é de Adorno) o conhecimento da realidade social não é negatividade sem mais, repulsa abstrata. Tem conteúdo, precisamente aquele que a pesquisa permite discernir. É nisso que entra o outro lado da questão. É que, na perspectiva de Adorno, é fundamental aquilo que desponta à frente em futuro indefinido, como possibilidade intrínseca ao próprio processo regido pelo movimento do capital. Não significa encerramento (em todas as acepções do termo) do destino, mas possibilidade de abertura não apenas na promessa como também em seu cumprimento.

Em conjunto, estamos diante de dois modos de pensar com difícil (embora, como já vimos, possível em alguns pontos) denominador comum. Em Weber, tudo se dá por linhas (a rigor, vetores) retas e inequívocas, em paisagem clara. Em Adorno, entramos em ambiente marcado pelas gradações sutis de figuras em chiaroscuro, não há gesto seguro, cada movimento abre um leque de consequências. Não por acaso Weber se dedica a abrir terreno para a afirmação peremptória, enquanto Adorno procura encontrar no interior do próprio objeto sua negação, não meramente formal senão material, dotada de conteúdo. Para Adorno, mais do que via inescapável o processo em curso desenha uma forma de sociedade, uma forma compacta, vulnerável contudo. Vulnerável porque é forma social, que não subsiste sem satisfazer os requisitos básicos de sua própria reprodução, sempre problemática, marcada por hiatos internos. Por mais compacta que ela se apresente e se revele resistente ao confronto direto, os hiatos e as resistências intrínsecas à sua dinâmica interna em cada momento multiplicam os pequenos pontos de vulnerabilidade, ocultos e só acessíveis sob condições muito exigentes. A mudança almejada depende de algo muito mais sutil e difícil do que o golpe de vista incisivo que Weber cobra do estadista, figura exemplar para ele. O que se exige é a persistente construção de uma circunstância que permita associar a palavra certa ao gesto quase imperceptível porém preciso, no átimo de tempo certo, oportuno, para com isso desatar o nó mais remoto e desencadear o processo de mudança radical, embora oculto no início. Uma mudança que não exige êxtases catastróficos e melhor corres ponde ao deslocamento e substituição do conjunto de mediações pelas quais passa o movimento do conjunto. Algo como uma revolução low profile, condensação de múltiplos atos, insignificantes quando isolados.

Não por acaso o tema da oportunidade é central em Adorno, desempenha nele papel análogo ao da contingência em Weber. Em Weber encontramos o gesto poderoso, heroico, da criação revolucionária (o termo é dele) de novas 
regras orientadoras da conduta, sendo elas regidas por valores que operam como critério de avaliação e seleção num campo de fenômenos. Em Adorno, temos o gesto mais afinado (stimmig, diria ele, em termo que designa afinação e também, de modo mais indireto, tempo certo, ajustado), impelido pela prontidão mais atenta e pela oportuna suavidade no toque de um músico, como ele era. Enfrentar o desafio manifesto, em Weber. Decifrar a promessa que, apesar de tudo, reluz no horizonte, em Adorno. Enfrentar, com risco de derrota na passagem do possível para o inexorável, em Weber. Decifrar, na difícil busca do outro significado que a imperativa positividade vigente porfia por ocultar, em Adorno. Captar o sentido, contingente em princípio, pois de outro modo nem sequer haveria como agir, de ações que se articulam conforme diretrizes cada vez mais estreitas e inequívocas, em Weber.

Em Adorno o processo de reprodução de complexos de relações sociais que se organizam em sociedade passa pelas formas que tais relações neles assumem. Importa ver essas formas em sua conexão com o que se poderia chamar de seu conteúdo ou sua matéria, precisamente tais relações. E essa conexão não é dada diretamente por constrangimentos impostos por escassez econômica ou por imperativos do poder político (como poderia dizer um weberiano apressado) nem pelo modo de geração e distribuição do produto (como poderia responder um marxista apressado), antes pela integração dessas duas ordens de organização de posições no espaço social em processos mais complexos, que passam pela dimensão cultural. Há uma tradução fundamental envolvida, que confere significado àquela conexão. Consiste ela em converter configurações de relações sociais em configurações significativas, mediante a forma. É conversão problemática, contudo, porque regida por uma conexão que só admite referência àquilo que importa para a reprodução do conjunto. É nesse ponto que entra a análise crítica, para não somente decifrar essa teia de significados como ir além dela, ao percorrer todo o caminho que permite entender as formas sociais como formas. Ou seja, como expressões de relações que, bem examinadas, podem denunciar descompassos e insuficiências no processo todo pelo qual se reproduz no tempo o complexo social envolvido.

\section{UM ELO INSUFICIENTE}

Se para Weber a gradativa racionalização dos sentidos da ação (mais exatamente, de seu encadeamento) vai estreitando suas vias e com isso torna mais difícil sair delas e buscar outros rumos, em Adorno o problema ganha outros contornos. "Abre-te, Sésamo, quero sair" é lema irônico adotado com gosto por ele. Nesse espirituoso lema, dirigida na origem ao fechado regime polonês no apósguerra, transparece o problema da saída para Adorno. Como sair quando não se está restrito a via única como em Weber, mas se está envolvido em configurações formais em constante mudança? As mais leves modificações no conteúdo social reverberam em múltiplas formas, somente restritas em sua variedade pelos li- 
mites impostos pela configuração do conteúdo por um lado e, por outro, pela distribuição de poder e pelas formas de seu exercício. Mais do que o golpe de vista preciso que Weber atribui ao líder político e que também vale para o pesquisador, em Adorno torna-se necessária a máxima finura na percepção dos contornos do objeto. Junto a isso, a máxima mobilidade no acompanhamento do modo como o jogo de suas mudanças formais desenha um complexo de relações entre as formas assumidas e aquilo que lhes confere figuras próprias, sua matéria.

Devemos, então, concluir que os dois autores se aproximam fortemente, ao dar atenção, ambos, ao problema da rigidez crescente dos âmbitos de ação? Não é bem assim. A rigidez weberiana, como vimos, advém do estreitamento do campo de opções significativas. Já aquela em que pensa Adorno é mais da ordem da imobilização, da conversão do dinâmico e mutável complexo de relações em figura estática, reificada, presa fácil do controle na sociedade administrada sob o império da comensurabilidade generalizada no capitalismo avançado. Cumpre lembrar que, enquanto Weber fala em racionalização como processo em curso e de racionalidade como orientação característica de ações, Adorno fala em racionalidade como modo social de efetivação da razão, posto que para ele a razão não é atributo de entes abstratos, e sim princípio de organização de relações. Ora, a racionalidade em Adorno pode ser objetivamente incompleta, fraturada e, nesse sentido, falsa. Aqui como em outros momentos Adorno revela o quanto sua reflexão está impregnada pela fundamental intuição de Marx, de que antes de falar de entes ou processos sem mais cabe concentrar a atenção no modo como eles concretamente aparecem em cada passo do movimento da sociedade, que cabe desde logo desvendar.

Efetivamente, é na relação do par forma e conteúdo com a realidade social mais abrangente que se põe a questão da determinação, no sentido de efetiva qualificação do objeto enquanto objeto, no interior do processo em que está inserido. Ela se dá mediante a resolução em cada momento dos compassos ou descompassos entre os termos daquela relação. Cabe aqui lembrar que a relação apontada acima, entre o objeto particular de análise e o todo social como entorno mais abrangente distingue de maneira drástica os dois modos de pensar. Em Weber, a questão mal se põe e quando se apresenta é para ser contestada com a afirmação de que não há totalidade envolvente e sim uma multiplicidade inesgotável de fenômenos. Toda a sua atenção se concentra nos cursos efetivos ou possíveis de ação pontual e em suas consequências. Daí a ênfase na contingência. Em Adorno, é questão crítica central. A totalidade social desempenha em Adorno papel análogo à oclusão significativa pela racionalização em Weber. O todo não é dado, mas é possível e ameaçador, como limite. É a persistente sombra da anulação do particular mediante sua subordinação ao geral. Mais precisamente, à sua lógica, o que, na mesma linguagem que a da 
reprodução, seria subsunção como imposição da lógica dominante, categoria central não explorada aqui.

\section{FORMA E MOVIMENTO}

Tudo o que foi dito até agora envolve uma ideia básica, essa sim inteiramente explícita em Adorno. É a ideia de movimento. Claro que esse termo não tem direta referência física, de mudança contínua de posição no espaço e no tempo. Menos clara é sua acepção adequada. Sustentarei aqui que, para além de entender-se o movimento no registro mais genérico, de alteração de posições recíprocas num conjunto ou de mudança direcional inscrita em processo, naquilo que nos interessa em Adorno a referência concerne à modificação (talvez fosse melhor dizer desdobramento) de formas. Em suma, de transformação, na exata acepção de passagem de uma forma a outra em determinado intervalo de tempo. Modificação determinada, contudo, inseparável de conteúdos sociais igualmente determinados. Qualidades concretas em ambos os polos. O movimento que interessa a Adorno assemelha-se mais ao jogo de imagens de fugidias peças móveis de caleidoscópio do que a uma locomotiva weberiana, bem construída e firme nos trilhos. Além de envolver a atenção mais móvel e mais penetrante, isso exige evitar o fácil equívoco de conceber forma e conteúdo (ou matéria; os termos são usados aqui como equivalentes) como dualidade, quando ambas são faces inseparáveis do mesmo processo. Aquilo que demanda atenção é precisamente o que poderíamos denominar materialidade da forma por um lado e figuração da matéria, pelo outro. Ou seja, constituem conjuntamente a substância mesma do processo, ao estar no núcleo de seu movimento. Isso supõe primazia do conteúdo em relação à forma do ponto de vista genético e necessidade (ou seja, condição para a reprodução) recíproca do ponto de vista estrutural.

Talvez caiba aqui, do ponto de vista do conhecimento preciso da sociedade em Weber e Adorno, uma referência a uma aproximação, essa sim inequívoca, entre ambos. É que, em um caso tanto como no outro, a armação conceitual e o modo de se valer dela em cada momento não se esgotam nas formulações literais que revestem no momento de sua formulação. É o oposto: são flexíveis e elásticas o bastante para enfrentar questões que só se apresentarão muito depois. Quando Weber fala do carisma do líder ungido pelo grupo poderia, agora, também falar da exacerbação da imagem e da presença de determinadas figuras mediante processos de produção de imagem muito mais complexos do que a construção original do carisma. E, quando fala de burocracia, é a multiplicidade e não a unidade de seus modos de composição que importa, mais do que o modelo prussiano, o mais nítido em sua época e por isso mais apropriado para a construção de um tipo ideal exemplar. E Adorno, quando fala da indústria cultural, não limita sua atenção a uma configuração do fenô- 
meno em certo momento, oferece perspectiva maior para pensar mais a fundo o modo de organização e de funcionamento (ou, por outro ângulo, de propriedade e de controle) de complexos de comunicação com os quais ele nem podia sonhar. Quem tem a capacidade de iniciativa, qual é seu modo de operação e o que produz eram questões centrais quando da construção do conceito de indústria cultural. Questão análoga se apresenta hoje, com relação ao complexo digital-informático, sempre lembrando que estamos aqui diante de componente nuclear no tipo de sociedade que Adorno se propõe examinar. A burocracia weberiana e a indústria cultural adorniana desempenham ambas papéis centrais em seus esquemas analíticos: a primeira como expressão máxima daquilo que identificava como quadro administrativo voltado para a gestão de qualquer organização complexa, e a segunda como expressão máxima da centralidade de construções ideológicas necessárias para a reprodução de sociedades regidas pelo capital.

A razão daquela convergência de nossos dois autores consiste em que ambos compartilhavam uma preocupação que conferia densidade ao seu pensamento. E o fazia ao orientá-los para além do momento presente e para buscar meios de discernir tendências no mundo social que os desafiava. É bem por isso que a ênfase em tudo que vimos até aqui tem como ponto nodal a visada de cada um deles para o futuro.

Olhar para o futuro. Para ambos o cenário que contemplam e do qual buscam os sinais de uma continuidade problemática é dinâmico, não oferece descanso. Se Weber vê uma linha que aponta para a consumação de algo já inscrito no presente, Adorno tem em vista imagem diferente e bem menos nítida, para usar termo que Weber apreciaria. Nem poderia ser de outro modo, quando em vez da continuidade a ênfase se põe na ruptura continuada, impelida por aquilo que ele em certo momento denominou vontade de mudança. Não há voluntarismo nisso. É que a mudança e o impulso para a atingir já são eles próprios promessas, que conjuntamente compõem a promessa maior, de formação de uma sociedade emancipada povoada por humanos livres. Sem desfecho discernível agora, sem qualquer segurança. O que se pode fazer aqui e agora é promover a acumulação de diminutas modificações até se condensarem em mudança maior, engendrada por aquilo que deve se formar ao longo do processo, uma humanidade capaz de ter vontade para tanto. Difícil promessa.

Não se trata em Adorno de promessa vã, porém. É resposta crítica à separação forçada daquilo que só junto faz sentido. Inscrita na posição crítica está a ênfase na aproximação como que assintótica das particularidades, sem se perder na fusão em nova identidade que anula a diversidade ou no geral que absorve o particular. Aproximação daquilo que foi separado na instância que mais importa como ponto de partida e como desfecho da análise, o modo como a sociedade se organiza. Se nessa sociedade o indivíduo se divide sem síntese possível em homem e cidadão, se o valor de uso se confronta ao valor de troca 
a ponto de eventualmente ser substituído por ele, se (para usar exemplo caro a Adorno) a música se divide em não qualificada, popular, e qualificada, de elite, se enfim tudo se rompe em pares de opostos estanques, sem conciliação e sem contradição, tem-se um grave desafio ao conhecimento social. Por um lado há a solução de incorporar a fragmentação no próprio esquema analítico, como faz Weber de maneira ainda discreta se comparado com os partidários mais radicais do "individualismo metodológico" que viriam mais tarde. No outro polo a busca de solução desemboca na imagem da sociedade como bloco, não necessariamente compacto. Claro que entre os clássicos Durkheim é o que mais se aproxima disso, com mais finura do que muitos dos que viriam depois, incluindo os partidários do sistema social como conceito central. Com toda a sua aversão por sistemas e totalidades, Adorno cultivou discretamente uma certa simpatia por Durkheim, coisa que não reservou para Weber, aparentemente o mais próximo intelectualmente, porém mais distante em seu modo de pensar e de ser. Um pensamento marcado por um realismo severo e intransigente, que se manifesta por frases contundentes e com alvo preciso, em estilo inteiramente alheio a Adorno: "É ridículo atribuir ao alto capitalismo atual qualquer afinidade com 'democracia' ou mesmo com 'liberdade', em qualquer sentido do termo". Isso potenciado por uma inclinação mais voltada para uma aristocracia idealizada, diferente daquela dos barões da terra e os da indústria alemães, do que para uma burguesia da qual proclamava ser membro, embora a desprezasse.

Alto capitalismo. Weber estava muito atento a isso não com atração ou repulsa e sim com isenção valorativa, sem se surpreender com nada. Para Adorno, tratava-se daquilo que imprimia sua marca em tudo e exigia para seu conhecimento um trabalho em múltiplos níveis simultaneamente, do processo de produção até a ideologia, passando pela arte. Isso como se impõe ao se lidar com objeto multifacetado, ora compacto e resistente ora diáfano e fugidio. São os modos e as condições de reprodução da ordem do capital que atraem a atenção de Adorno. Importam as figuras mais finas desse processo, que devem ser capturadas em suas traduções para os diversos níveis da vida social.

No plano das relações sociais isso se manifesta em algo de suma importância. Trata-se da presença cada vez mais preponderante do interesse, a força desagregadora mais implacável de todas, e talvez também a mais naturalizada. Força que se vai impondo de modo inelutável em todas as relações sociais ao se intrometer entre elas e drenar energia de todas. E que, pelo fato de ser eminentemente desagregadora, contribui para aplainar o terreno para o predomínio da lógica da equivalência universal e, por essa via, da totalidade fechada como sistema. Aquela lógica traz consigo, como seu produto mais eminente, a supremacia generalizada da identidade sobre a multiplicidade de formas portadoras do particular em sua relação com o todo. Naquelas múltiplas formas reside para Adorno o núcleo mesmo da resistência e da ação transformadora. 
Central nesse trabalho crítico é desvendar o que é próprio a esse processo, cuja tendência consiste em culminar numa totalidade marcada pela indiferença. Nesta encontra-se a exata contrapartida da equivalência geral dos valores intercambiáveis própria ao capitalismo avançado e, por outro lado, do interesse generalizado e abstrato. Uma expressão social desse processo encontra-se naquilo que Adorno denomina frieza burguesa.

Nisso consiste o alvo final desse conhecimento crítico, que detecta as insuficiências da posição transformadora presente, enquanto convida a localizar os pontos em que tal ação ganharia condições para abalar o todo. Para tanto não basta simplesmente tentar soldar os fragmentos, tarefa eminentemente conservadora. Trata-se de mudar inteiramente a perspectiva e procurar em meio à fragmentação o movimento (pois é disso que se trata) não de ruptura sem mais e sim de polarização que confere conteúdo ao processo. Isso em vez de acompanhar, na melhor tradição analítica, a proliferação dos fragmentos e seus possíveis arranjos. Não se trata de mera inversão do curso da orientação analítica, mas de evitar a concentração do olhar nas relações entre entes isolados e procurar nas relações entre eles e o todo de que são parcelas (ou momentos do processo) a razão de ser da configuração particular.

Essencial na conclusão de toda a argumentação apresentada é considerar a ideia de que a resposta crítica (não linearmente positiva, portanto) à separação forçada não pode ser a integração igualmente forçada, e sim o mais difícil, a aproximação - por deslocamentos regrados as coisas, por deliberação consciente as gentes. Pois aproximação não é mera fusão, só ganha sentido quando se preserva a integridade dos participantes, o que só pode ocorrer quando seus gestos são espontâneos e livres. No horizonte brilha a redenção, que não se confunde com a salvação ou qualquer outra referência religiosa, mas é promessa redimida, o resultado inteiro da vontade de mudar. Não redenção como conformidade às condições do mundo, e sim como a agora impossível, porém teimosamente procurada experiência de plenitude na boa hora, promesse $d u$ bonheur.

Dois autores de primeira linha, o mesmo mundo visto de perspectivas diversas, que compõem um perturbador jogo de aproximações e afastamentos, com o contraste entre ambos se sobrepondo passo a passo aos acenos conciliatórios. De um lado o realismo puro e duro, a disposição heroica para enfrentar o "semblante severo do dia", a preferência por conceitos talhados em madeira dura como o sólido e incisivo tipo ideal, junto à busca sistemática da expressão conclusiva da análise dos fenômenos sociais. Tudo isso se apresentando sob o influxo de atitude energicamente resignada, se for possível propor essa fórmula. Coisa essa, de resto, que não violenta o modo de ser e de pensar de Weber, expressivamente traduzido na sentença do escritor suíço Conrad Ferdinand Meyer: "Não sou livro bem raciocinado, sou um humano com sua contradição". Isso desde que se considere o decisivo, a saber, que na ânsia de 
se livrar do contraditório ele acabasse, como fez, depositando todo o peso na condição de humano, que contudo sabia não suportar tanto. Nada de voos utópicos, e também nada de derrotismo, ainda menos de ação vácua, desprovida de fundamento sólido. Resignação, sim, mas enérgica como se disse acima, traduzida em ação bem direcionada e isenta de ilusões, com a ajuda de conhecimento rigoroso. Afinal, conhecer o destino é passo decisivo para lidar com ele, para usar sua expressão. Tudo diferente de Adorno, esse apreciador de rios com seus meandros mais do que de estradas retilíneas. Seu problema não era tanto o de fortalecer o homem para dominar sua contradição, e sim liberar a contradição para abrir caminho à saída do humano de sua condição não emancipada. Consoante isso, sua questão não era fazer o possível em busca do impossível e sempre estar pronto a prestar contas de suas ações, como Weber esperava da alta política. Também não há espaço para a utopia, até porque ele estava mais atento ao mundo distópico em que vivia. Para ele a tarefa consistia no trabalho de formiga de percorrer a rocha dura penetrando em todas as suas fendas, por minúsculas que sejam, para mostrar que ainda vibra dentro dela o movimento a que resiste compactamente. E vibra em pontos inesperados, a ser teimosamente procurados para dar alento aos golpes diminutos, porém precisos, que anunciam a mudança possível, apesar de tudo - e nesta última expressão encontra-se a promessa.

Destino que exige dignidade frente ao inexorável, promessa que exige persistência perante o impossível, em ambos os casos sem ilusões e sem desânimo. Tarefas difíceis, mas que ninguém espere dessas figuras modelares que diante disso esmorecessem.

Recebido em 5/3/2020 | Aprovado em 7/8/2020

Gabriel Cohn é professor emérito da Universidade de São Paulo. De I 985 a I 987 foi presidente da Sociedade Brasileira de Sociologia e em 2005-2006 da Associação Nacional de Pós-Graduação e Pesquisa em Ciências Sociais (Anpocs). 


\section{NOTA}

I O texto está baseado na consulta a diferentes publicações, sendo impossível especificar aqui uma lista exaustiva. As referências principais se encontram em Weber (1973) e Adorno (2008, 2009). Reflexões minhas sobre esses dois autores se encontram em diferentes lugares, em particular em Cohn (2003, 2017).

\section{REFERÊNCIAS BIBLIOGRÁFICAS}

Cohn, Gabriel. Weber, Frankfurt: teoria e pensamento social. Rio de Janeiro: Azougue, 2017.

Cohn, Gabriel. Crítica e resignação: Max Weber e a teoria social. São Paulo: Martins Fontes, 2003.

Adorno, Theodor. Dialética negativa. Rio de Janeiro: Zahar, 2009.

Adorno, Theodor. Minima moralia. Rio de Janeiro: Azougue, 2008.

Weber, Max. Gesammelte Aufsätze zur Wissenschaftslehre. Tübingen: Mohr, I973. 


\section{WEBER, ADORNO E O CURSO DO MUNDO}

Resumo

Dois temas contrastantes, do destino e da promessa, caracterizam as posições de Max Weber e Theodor W. Adorno. Ambos compartilham preocupações básicas a respeito da natureza e das tendências de sociedades modernas, marcadas pelo Estado nacional no âmbito político, pelas organizações privadas racionalmente organizadas no âmbito econômico e pelo predomínio de empresas privadas no âmbito da produção e distribuição de formas com conteúdo cultural. Para fazer frente aos problemas analíticos envolvidos, ambos concentram a atenção, por ângulos diferentes e incompatíveis, na dimensão significativa dos processos sociais. No presente artigo argumenta-se que, a despeito dessas aproximações e do frequente argumento de que Adorno deve muito a Weber, ambos enfrentam problemas similares mediante linguagens distintas, com base em pressupostos igualmente distintos e sem tradução direta entre si. Algumas implicações disso são examinadas.

\section{WEBER, ADORNO AND THE COURSE OF THE WORLD}

Abstract

Two contrasting themes, destiny and promise, characterize the positions of Max Weber and Theodor W. Adorno. Both share basic concerns about the nature and tendencies of modern societies, marked by the nation state in the political sphere, by rationally organized private organizations in the economic sphere, and by the predominance of private enterprises in the sphere of production and distribution of forms of cultural content. In response to the analytic problems involved, both focus attention - from different and incompatible angles - on the meaningful dimension of social processes. This article argues that despite these approximations and the frequent argument that Adorno is heavily indebted to Weber, both confront similar problems through distinct languages, based on equally distinct premises with no direct translation between them. Some implications of this are examined.
Palavras-chave

Teoria social;

sociologia alemã;

Max Weber;

Theodor Adorno.

\section{Keywords}

Social theory; German sociology; Max Weber; Theodor Adorno. 